\title{
Journal of Engineering
}

journal homepage: www.joe.uobaghdad.edu.iq

Number 11 Volume 24 November 2018

\section{Water Resources and Surveying Engineering}

\section{Accuracy Assessment of Stonex X-300 Laser Scanner Cameras}

Luma Khalid Jasim

College Of Engineering, University of Baghdad

E-mail:j.lumakhalid@yahoo.com

\begin{abstract}
Assessment the actual accuracy of laboratory devices prior to first use is very important to know the capabilities of such devices and employ them in multiple domains. As the manual of the device provides information and values in laboratory conditions for the accuracy of these devices, thus the actual evaluation process is necessary.

In this paper, the accuracy of laser scanner (stonex X-300) cameras were evaluated, so that those cameras attached to the device and lead supporting role in it. This is particularly because the device manual did not contain sufficient information about those cameras.
\end{abstract}

To know the accuracy when using these cameras in close range photogrammetry, laser scanning (stonex X-300) device is used to obtain photos of a board including (23) ground control points on it, those observed from two stations and adjusted by using equations of the 3D adjusted triangulation networks by lengths and angles (hybrid routine). (10) GCPs and (13) checkpoints were used to compare the Root Mean Square Error (RMSE) of checkpoints that result from using laser scan cameras with (RMSE) of the same checkpoints that result from using digital photos (Nikon 5200D).

The result of (RMSE) comparison was $(58.9 \mathrm{~mm}$.) in the $\mathrm{X}$ direction, $(10.5 \mathrm{~mm}$.) in the $\mathrm{Y}$ direction and $(0.09 \mathrm{~mm}$.) in the $\mathrm{Z}$ direction.

Key Words: Laser scanner, Digital camera, Close Range Photogrammetry, Bundle Adjustment, 3D triangulation network.

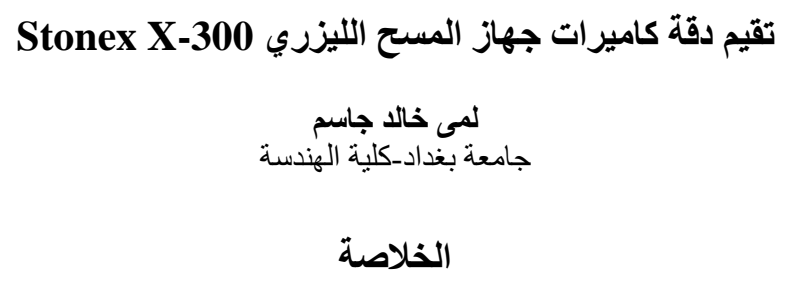

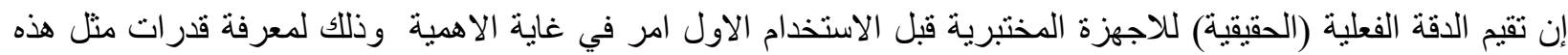

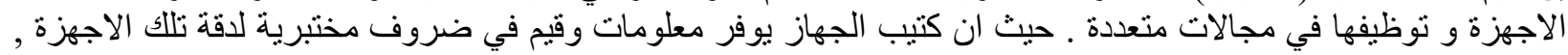

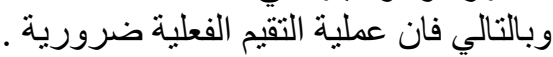

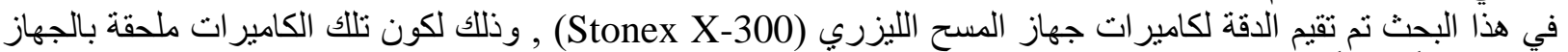
وتؤدي دوراً داعماً فيه, و هذا على وجها الخصوص لانه لان كتيب الجهاز لايحتوي على معلومات كافية عن تللك الكاميرات.

*Corresponding author

Peer review under the responsibility of University of Baghdad.

https://doi.org/10.31026/j.eng.2018.11.08

2520-3339 (C) 2018 University of Baghdad. Production and hosting by Journal of Engineering.

This is an open access article under the CC BY-NC license http://creativecommons.org/licenses/by-cc-nc/4.0/).

Article received: 7/9/2017

Article accepted: 25/1/2018 


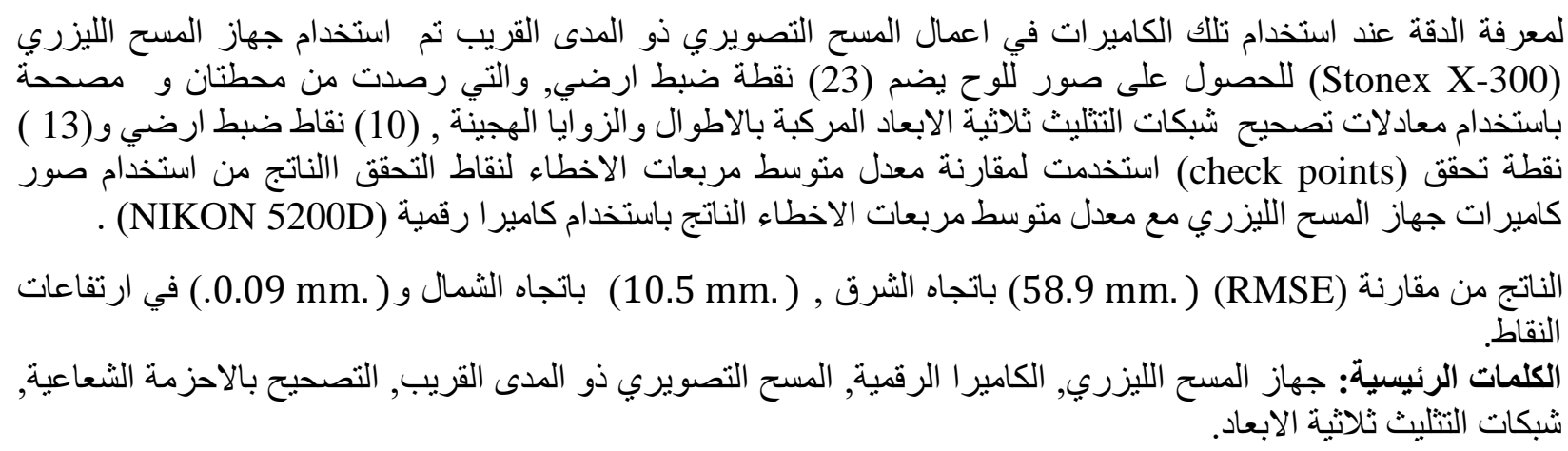

\section{INTRODUCTION}

Generally speaking in the close range photogrammetry 3D model of the number of certain points are determined based on two approaches:

- Approach A: plane surveying can be made through the use of field surveying instruments such as Total Station for the purpose of determining the 3D coordinates of certain points through the use of land surveying instruments requires a number of well-defined and precise (3D)[ horizontal and vertical ground control points (GCPs)].

- Approach B: can be done through the use of close-range photogrammetric technique simply by taking a minimum of two photos from two stations.

The precision of processing in this approach depends on the number and distribution of the ground control points. This research is using approach A to provide ground control points for approach B, used two data resource and compare between them.

Close range photogrammetry provides the possibility of getting the three-dimensional (3D) coordinates of an object from two-dimensional (2D) digital images in a fast, precise, reliable, flexible and economical way. This makes it an ideal tool for accurate industrial measurement, Aguilar, et al. 2005, Fraser, 1993.

\section{DIGITAL CLOSE RANGE PHOTOGRAMMETRY}

Digital close range photogrammetry is a technique for precisely measuring objects directly from photos or digital images captured with a camera at close range to the object. Multiple, overlapping images capturing from different stations, produces measurements that used to create accurate 3D models of targets. Atkinson, 1996, Easa, 1988, and Slama, 1980.

The digital close range photogrammetric projects are generally done through the use of a digital nonmetric camera through the implantation of the well- known collinearity equations Cooper, and Robson, 2001.

Each point has two collinearity equations, one for the(x) photo coordinate and the other for the (y) photo coordinate Ghoch, 1979.

The general form of the collinearity equation for $(\mathrm{x}, \mathrm{y})$ in close range photogrammetry having the following general forms: Wolf, and Dewitt, 2000.

$x-x_{o}=-c \frac{\left[m_{11}\left(X-X_{L}\right)+m_{12}\left(Y-Y_{L}\right)+m_{13}\left(Z-Z_{L}\right)\right]}{\left[m_{31}\left(X-X_{L}\right)+m_{32}\left(Y-Y_{L}\right)+m_{33}\left(Z-Z_{L}\right)\right]}=-c \frac{U}{W}$ 
$y-y_{o}=-c \frac{\left[m_{21}\left(X-X_{L}\right)+m_{22}\left(Y-Y_{L}\right)+m_{23}\left(Z-Z_{L}\right)\right]}{\left[m_{31}\left(X-X_{L}\right)+m_{32}\left(Y-Y_{L}\right)+m_{33}\left(Z-Z_{L}\right)\right]}=-c \frac{V}{W}$

Where:

$(\mathrm{x}, \mathrm{y})$, photo coordinates of the point.

$\left(\mathrm{x}_{0}, \mathrm{y}_{\mathrm{o}}, \mathrm{c}\right)$, interior orientation parameters(I. O.P).

$(\mathrm{m} 11, \mathrm{~m} 12, \mathrm{~m} 13 \ldots \mathrm{m} 3)$, elements of the matrix of rotation that are the rotation's function angles $(\omega, \varphi, \kappa)$ as shown in Fig. 2.

(XL, YL, ZL), three-dimensional coordinates of the camera station.

(X, Y, Z), the 3D coordinates of the object points as shown in Fig.1.

The parameters involved in the collinearity Eq. (1\&2) above are shown geometrically in Fig. $1 \& 2$.

\section{METHODOLOGY}

\subsection{Establishing Ground Control Points (GCPs)}

(23) Ground control points were established on a whiteboard, (10) GCPs and (13) checkpoints to use for triangulation and compute the error and as shown in Fig. 3.

\subsection{Observed Coordinates, distance, the horizontal and vertical angle of the control and the checkpoints}

The coordinates of points were observed by using Total station (Topcon (ES)) from two stations $(\mathrm{A}, \mathrm{C})$ as shown in sketch and Fig. 4

\subsection{Adjusted triangulation networks by lengths and angles (hybrid) using Matlab code.}

The adjustment code was used to adjust distances and angles to compute the corrected coordinate. The reference observation values that was observed by the total station was used as approximate value and use as input data to the Matlab code, Shanwer, 2017, to compute the adjusted coordinates and apply the assessment.

\subsection{Capturing photos}

- Two photos were taken to the board from stations (A, C) using a digital nonmetric camera (Nikon 5200D) as shown in Fig.5.

- Six photos were taken to the board from one station (B) using cameras of laser scanning (Stonex X-300) device as shown in Fig.6.

\subsection{Data processing}

Use of Leica Photogrammetry Suite 9.2 software, which is mainly consisting of camera calibration, resection and the computation of the adjusted 3D, coordinates of the required construction points Easa, 1988, as shown in Fig. 7\&8. 


\section{RESULTS AND DISCUSSION}

The results of the data processing using photos of Nikon camera by (LPS) software (RMSE) were computed as shown in Fig. 9.

The results of the data processing using two photos cameras' laser scan X-300 by (LPS) software (RMSE) was computed as shown in Fig. 10.

The result of (RMSE) comparison is $(58.9 \mathrm{~mm}$.) in the $\mathrm{X}$ direction, $(10.5 \mathrm{~mm}$.) in the $\mathrm{Y}$ direction and (0.09 mm.) in the $\mathrm{Z}$ direction as shown as in Fig. 11.

\section{CONCLUSION}

1. The end-lab of the photos delivered from Stonex X-300 cameras is approximately $25 \%$, therefore the accuracy of the outputs was less than those delivered from the photos of Nikon camera.

2. The results obtained from $X-300$ laser scan cameras deliver a low accuracy of $20.4 \mathrm{~mm}$. in $\mathrm{X}$ direction $3.4 \mathrm{~mm}$. in the $\mathrm{Y}$ direction and $0.4 \mathrm{~mm}$. in the $\mathrm{Z}$ direction. This kind of accuracy can be used in photogrammetry applications those need low precision requirements.

3. The coordinate $(\mathrm{X}, \mathrm{Y})$ could get from a single photo of cameras' laser scan X-300 with an accuracy of $\pm 5 \mathrm{~mm}$.

4. Photos of cameras' laser scan X-300 can be used for visualization with laser data and measurements that need less accuracy for photogrammetry.

5. The result of the comparison test with Nikon camera was $(58.9 \mathrm{~mm}$.) in the $X$ direction, $(10.5 \mathrm{~mm}$.) in the $\mathrm{Y}$ direction and $(0.09 \mathrm{~mm}$.) in the $\mathrm{Z}$ direction.

\section{REFERENCES}

- Aguilar, M.A., Aguilar F.J., and Agüera, F., 2005, The Evaluation of Close-range Photogrammetry for the Modelling of Mouldboard Plough Surfaces, Biosystems Engineering, vol. 90 No. 4, pp.397-407.

- Arias, P., Herraez, J., Lorenzo, H., and Ordonez C., 2005, Control of structural problems in cultural heritage monuments using close-range photogrammetry and computer methods, Computers and Structures, Vol.83,pp.1754-1466.

- Atkinson,KB. 1996, Close range Photogrammetry and machine vision.Caithness:Whittlesn Publishing.

- Cooper, M., and Robson, S., 2001, Theory of close range photogrammetry. In: Atkinson $\mathrm{KB}$, editor. Close range photogrammetry and machine vision. Caithness, Scotland, UK: Whittles Publishing: pp.9-51. 
- Easa, S.M., 1988, Estimating Pit Excavation Volume Using Nonlinear Ground Profile Journal of Surveying Engineering, Vol. 114, No. 2, pp.71-83.

- Fraser, C. S., 1993, A resume of some industrial applications of photogrammetry, ISPRS Journal of Photogrammetry and Remote Sensing, Vol. 48, No.3, pp. 12-23.

- $\quad$ Ghoch, S. K., 1979, Analytical Photogrammetry, Pergamon Press,New York.

- Shanwer, M. M., 2017, 3D Cultural Heritage Documentation Using Terrestrial Laser Scanning Technology, thesis.

- Slama, C. C., 1980, the Manual of Photogrammetry, 4th Edn. American Society of Photogrammetrists, Falls Church, VA.

- Wolf, P.R., and Dewitt, B.A., 2000, Elements of photogrammetry with applications in GIS. EEUU: McGraw-Hill.

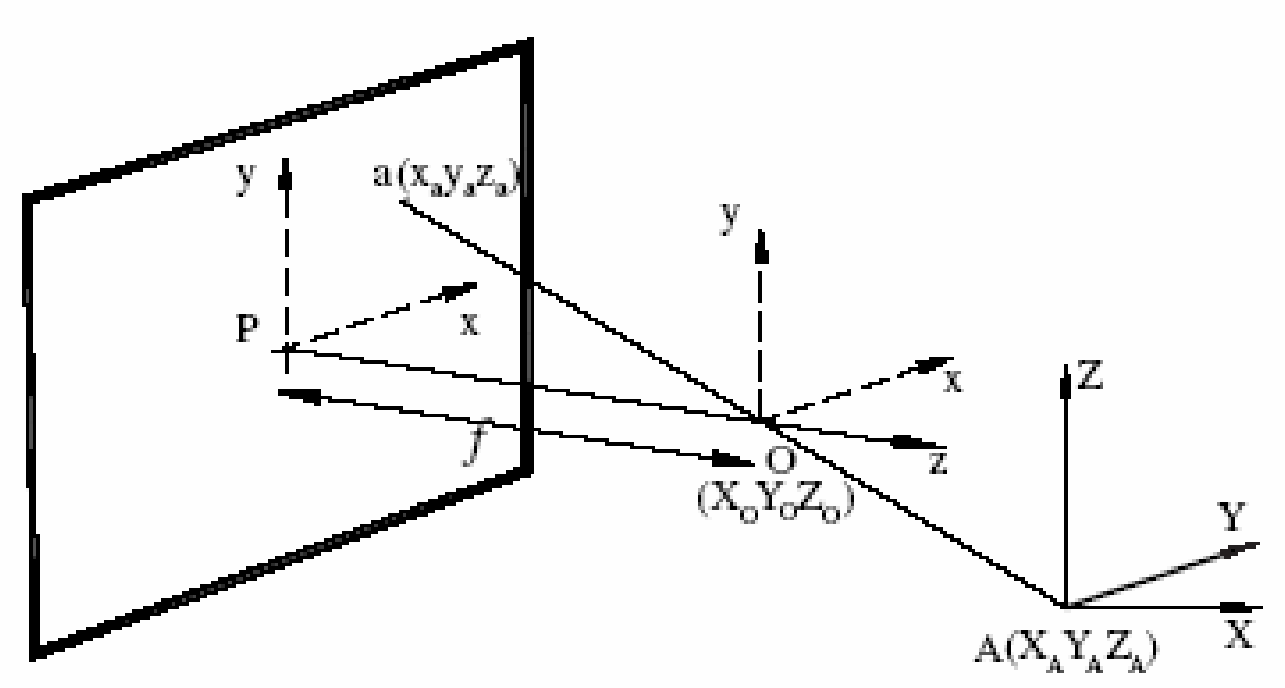

Figure 1. Central perspective of point A in close range photogrammetry, Arias, et al., 2005. 


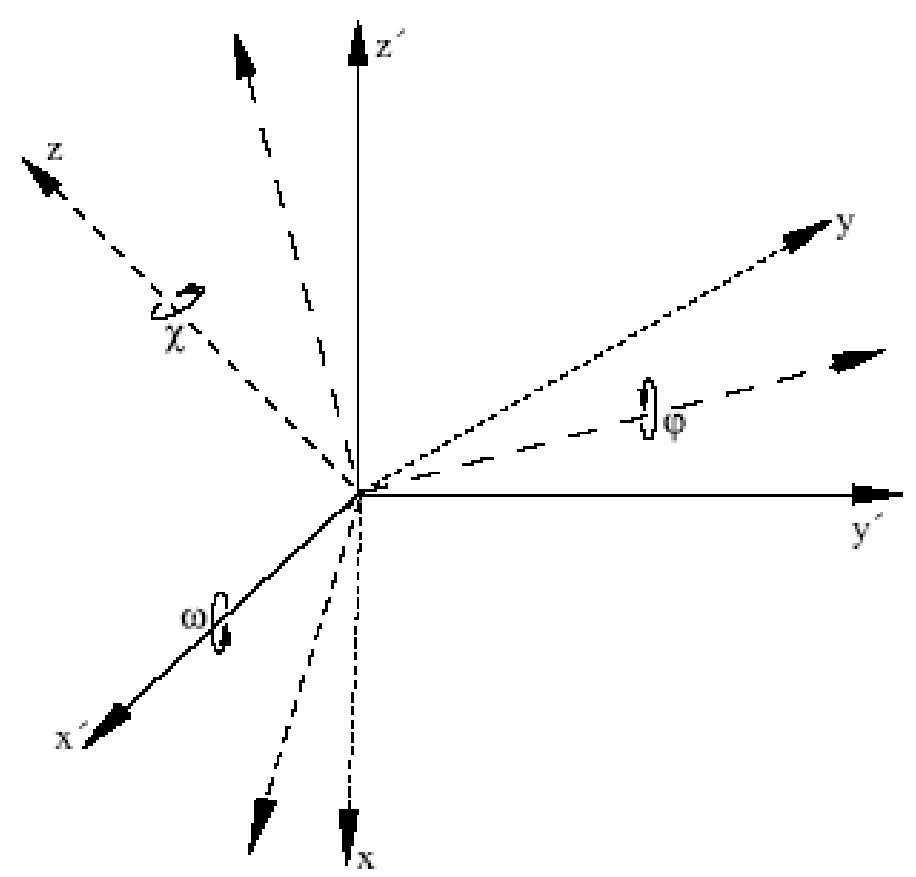

Figure 6. Rotation angles on the three axes (X, Y, Z), Arias, et al., 2005.

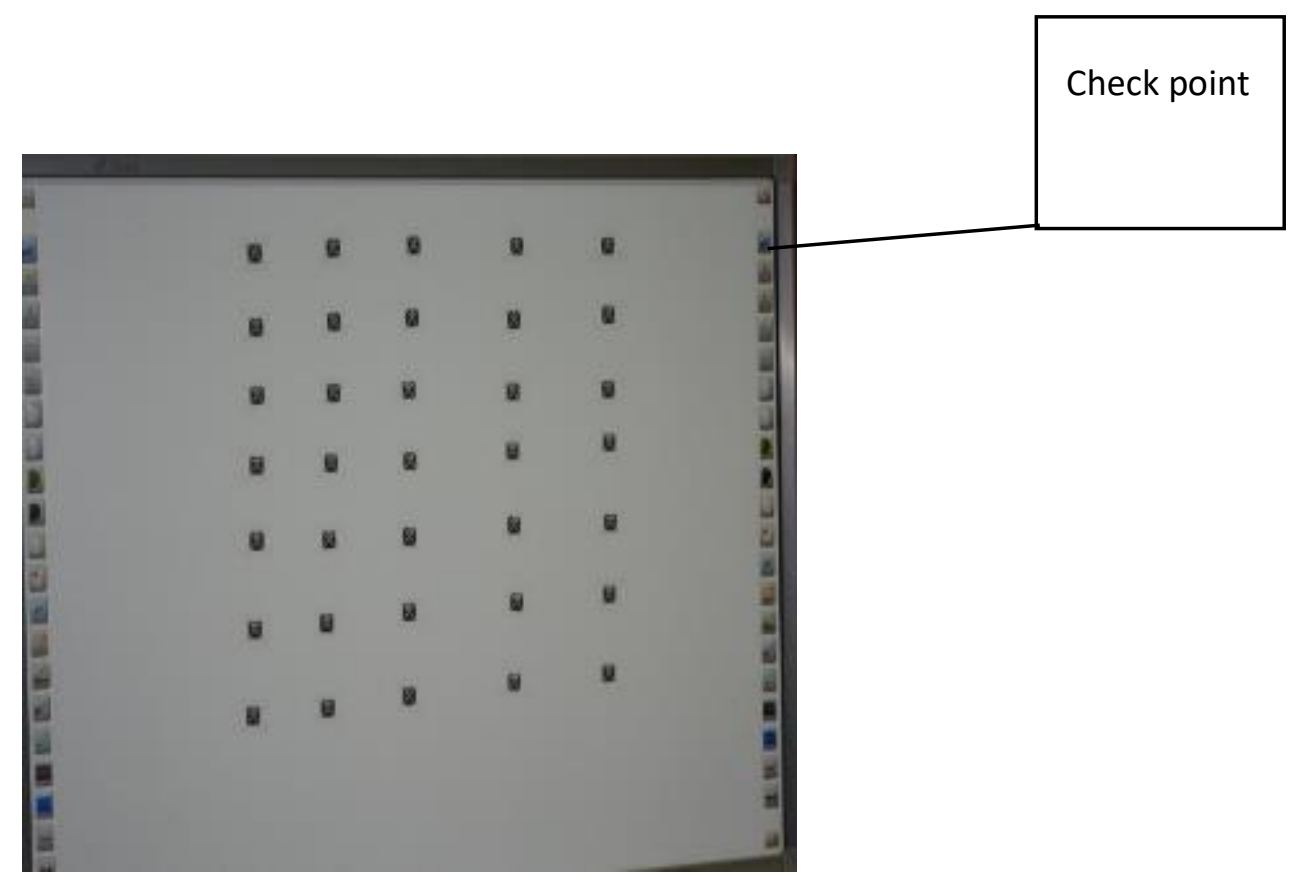

Figure 3. Distribution of (GCPS) and checkpoints. 

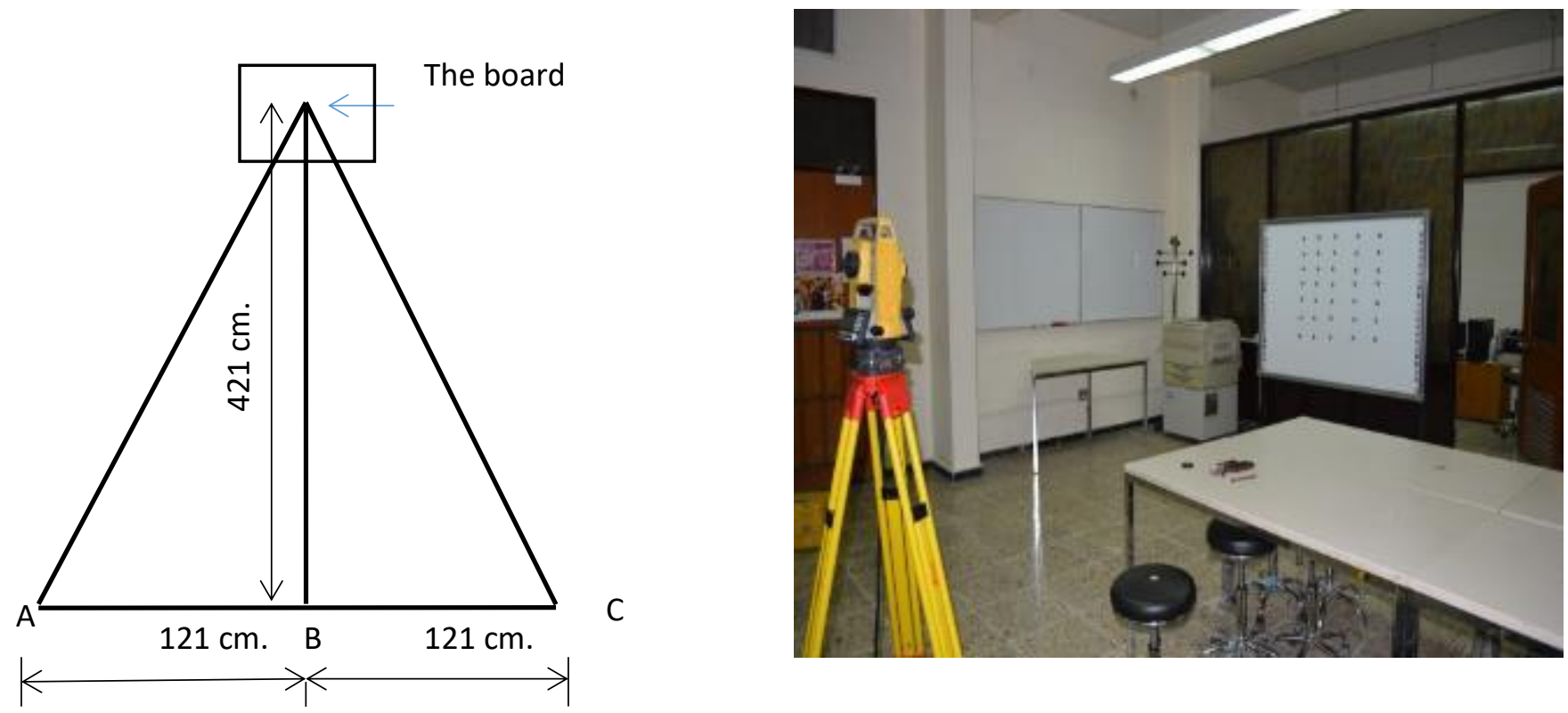

Figure 4. Sketch for stations.

\section{D5200}
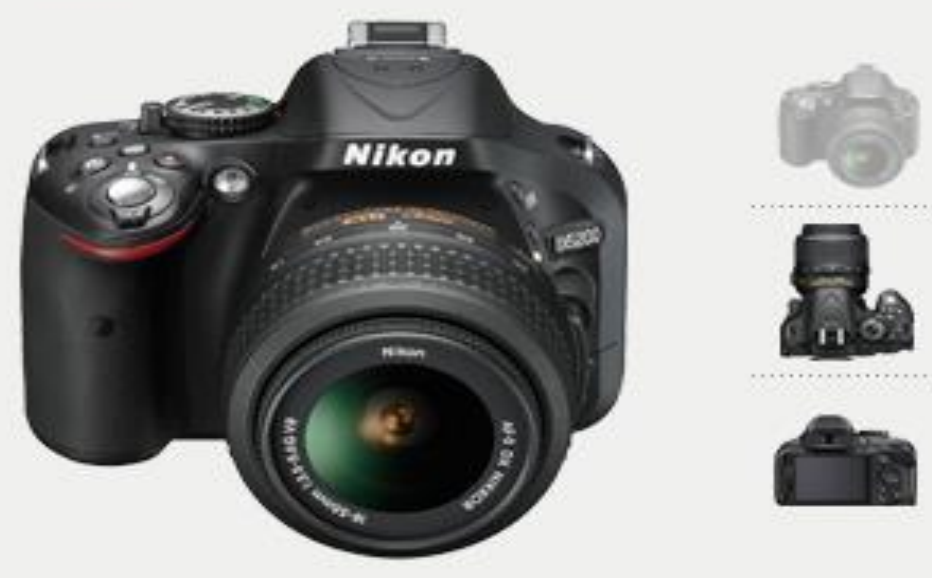

Figure 5. Nikon 5200D. 


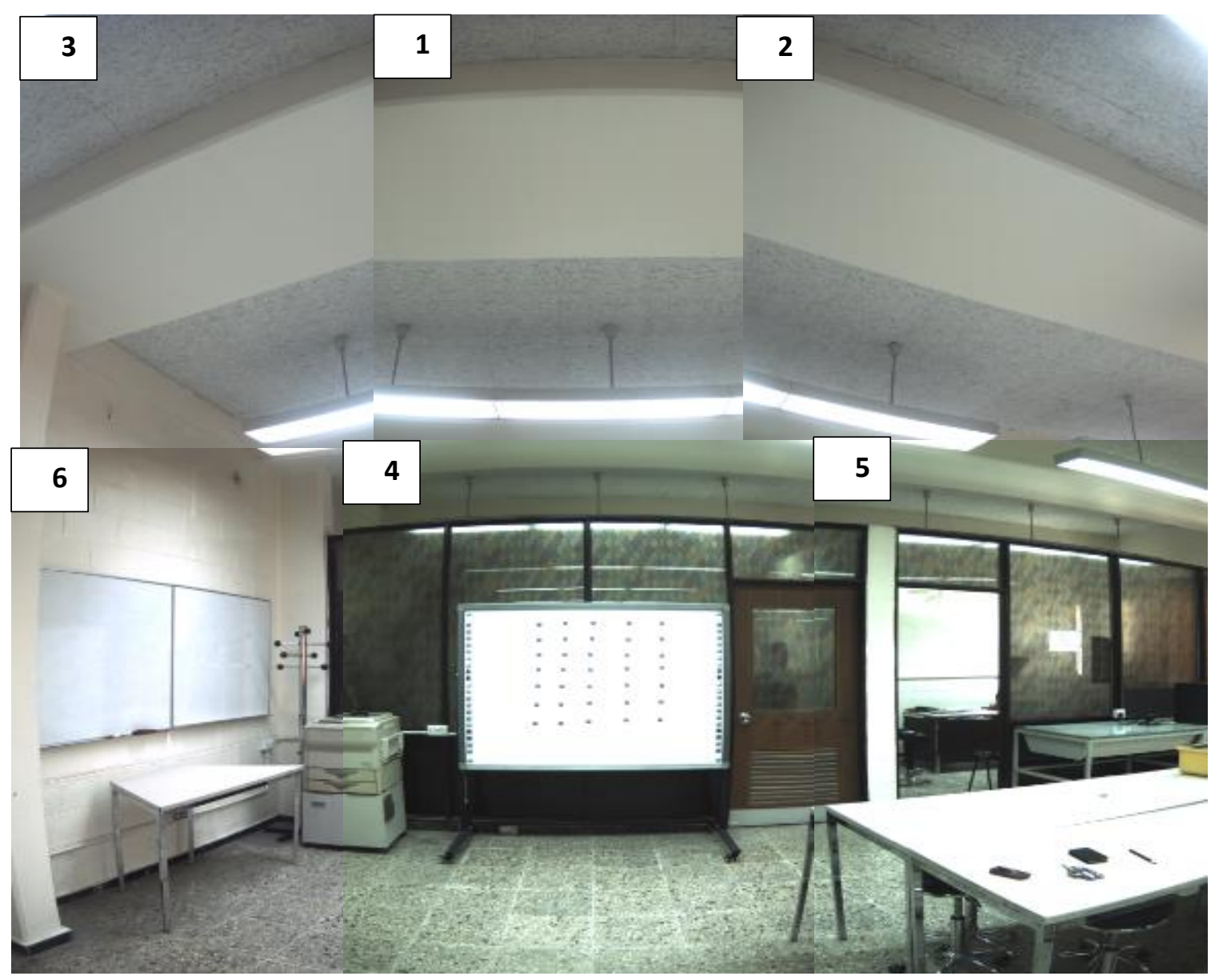

Figure 6. Photos from laser scan cameras.

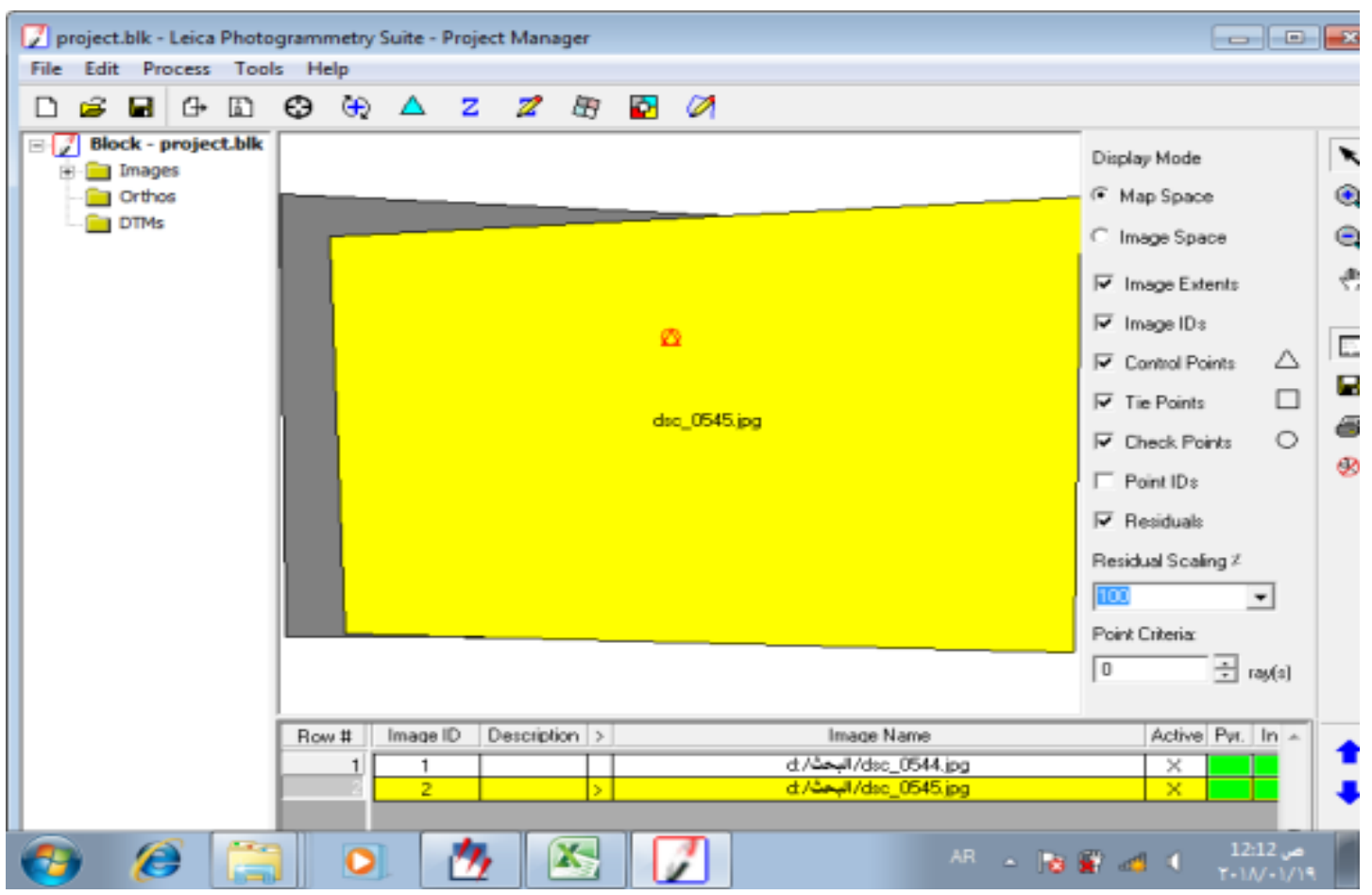

Figure 7. Windows of processing with LPS. 


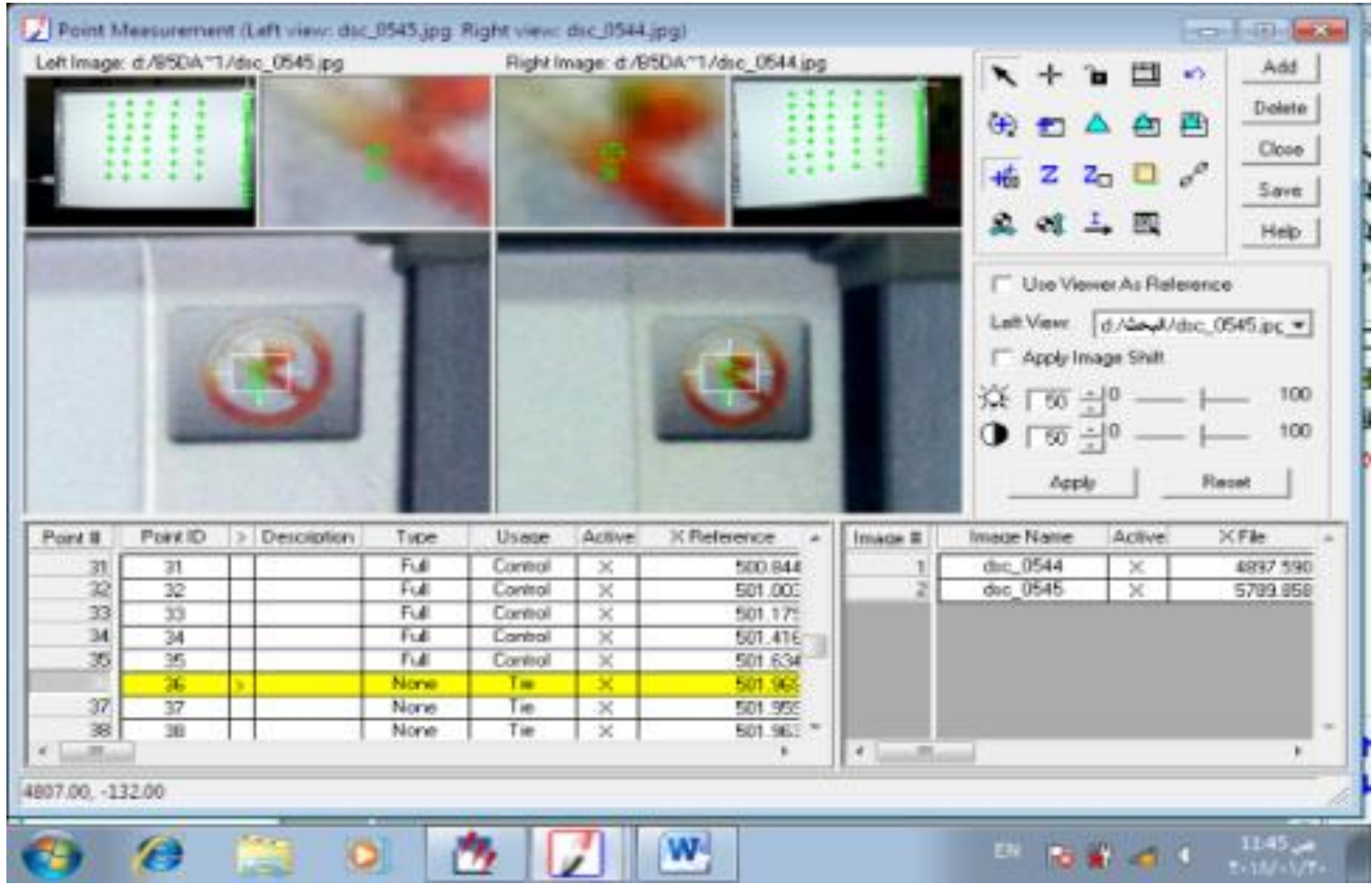

Figure 8. The window of processing with LPS.

Cheack Point FMSE:

Ground $\times: \quad 0.0001[1]$

Ground Y: $\quad 0.00010$ [1]

Ground Z: $0.0023[1]$

Feview..

Image $\times: \quad 0.6936$ [2]

Help

Image Y: $\quad 1.0892$ [2]
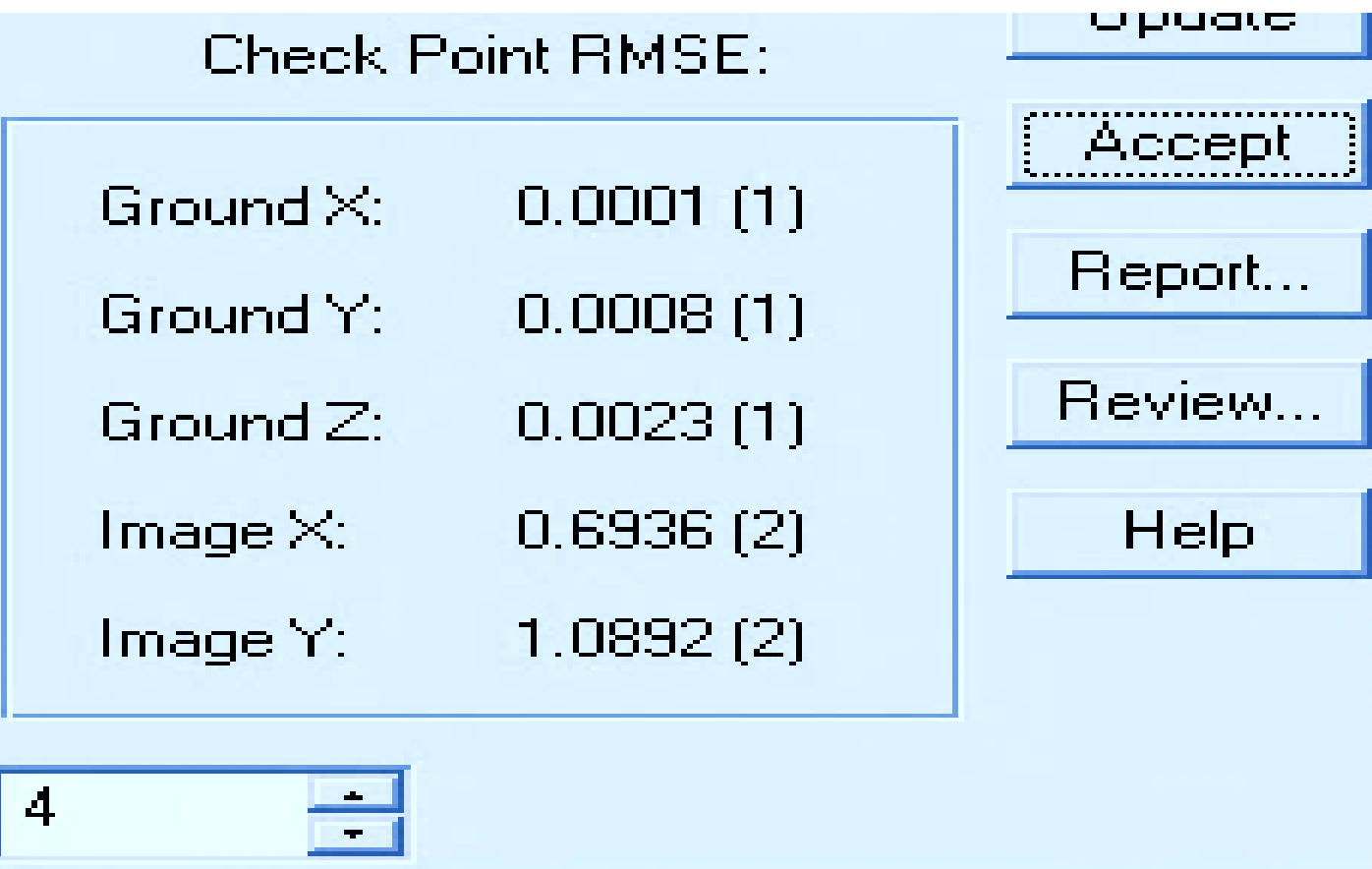

Figure 9. (RMSE) using photos of Nikon camera by (LPS). 


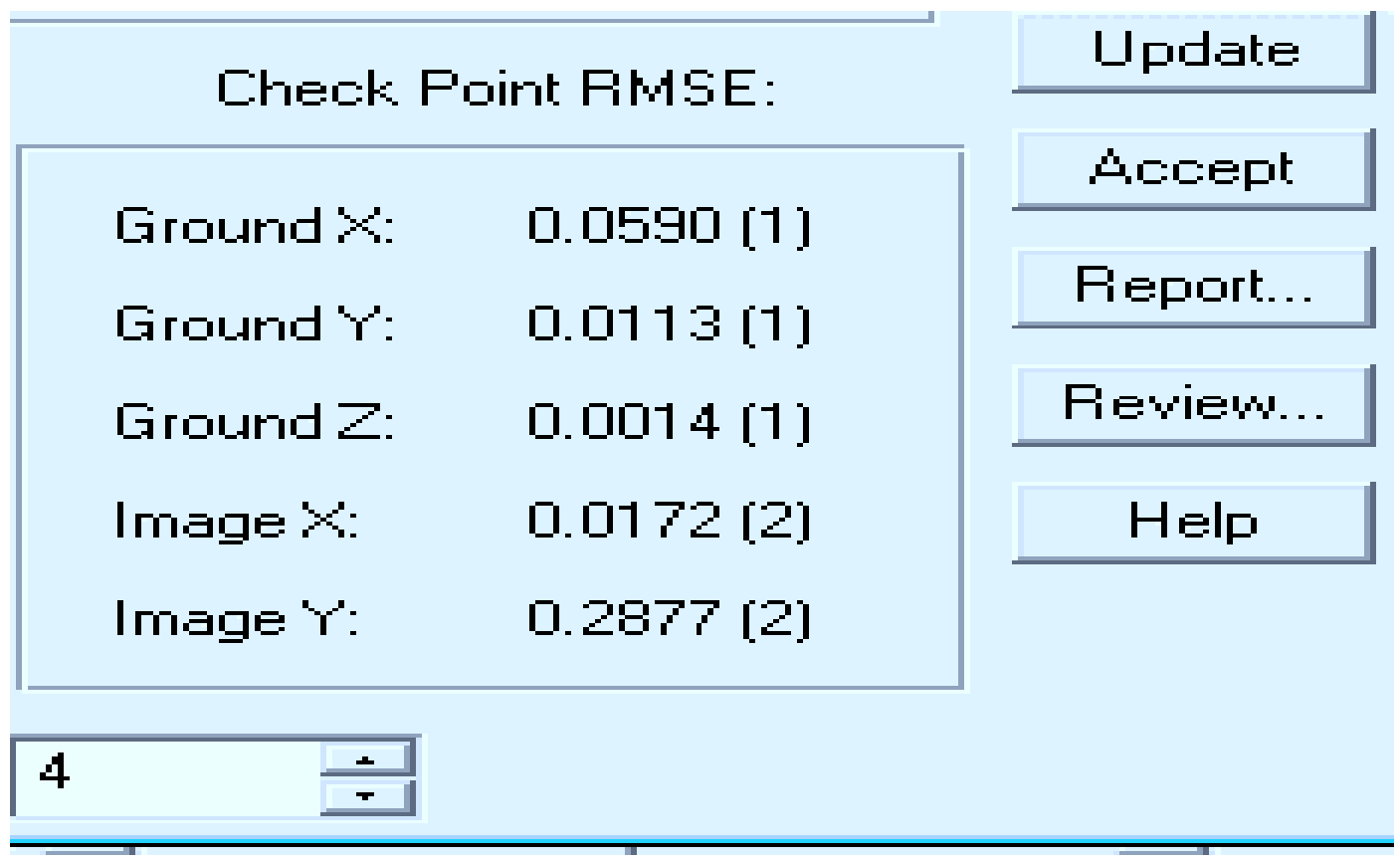

Figure 10. (RMSE) using photos of cameras' laser scan X-300 by (LPS).

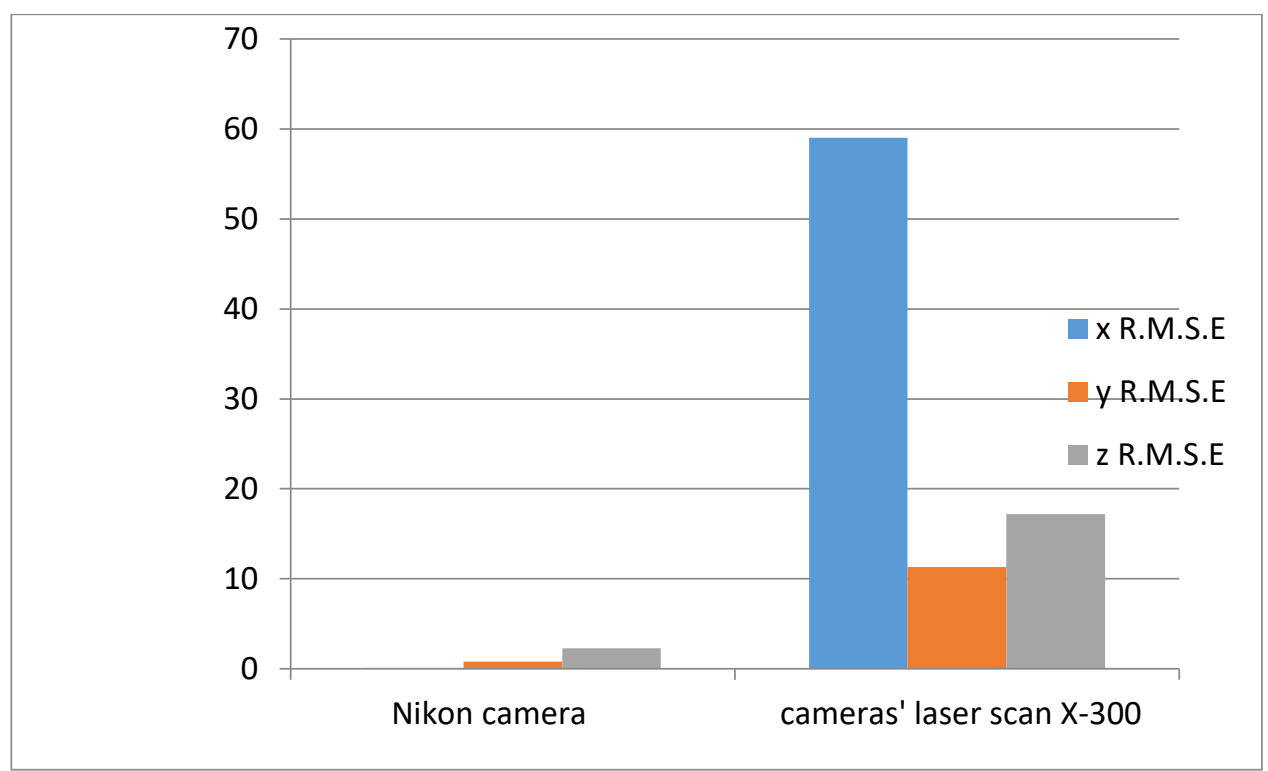

Figure 11. (RMSE) using photos of Nikon camera and photos of cameras' laser scan X-300 by (LPS) software. 
Table 1. Measured coordinates, distance, the horizontal and vertical angle of sample control and checkpoints (from station A).

\begin{tabular}{|c|c|c|c|c|c|c|c|}
\hline point & Distance m. & $\begin{array}{c}\text { vertical } \\
\text { angle }\end{array}$ & $\begin{array}{c}\text { horizontal } \\
\text { angle }\end{array}$ & $\mathbf{X ~ m .}$ & Y m. & $\mathbf{Z}$ m. & type \\
\hline 36 & 4.4090 & $87^{\circ} 33^{\prime} 02^{\prime}$ & $11^{\circ} 22^{\prime} 25^{\prime}$ & 501.9491 & 504.2812 & 31.7745 & control \\
\hline 37 & 4.4070 & $87^{\circ} 28^{\prime} 13^{\prime \prime}$ & $11^{\circ} 21^{\prime} 10^{\prime \prime}$ & 501.9386 & 504.2779 & 31.7512 & check \\
\hline 38 & 4.4020 & $87^{\circ} 26^{\prime} 30^{\prime \prime}$ & $11^{\circ} 36^{\prime} 44^{\prime}$ & 501.9432 & 504.2735 & 31.6592 & check \\
\hline 39 & 4.4010 & $87^{\circ} 20^{\prime} 17^{\prime}$ & $11^{\circ} 233^{\prime} 22^{\prime}$ & 501.9331 & 504.2644 & 31.6451 & check \\
\hline
\end{tabular}

Table 2. Measured coordinates, distance, the horizontal and vertical angle of sample control and checkpoints (from station C).

\begin{tabular}{|c|c|c|c|c|c|c|c|}
\hline point & Distance m. & $\begin{array}{c}\text { horizontal } \\
\text { angle }\end{array}$ & $\begin{array}{c}\text { vertical } \\
\text { angle }\end{array}$ & $\mathbf{X ~ m .}$ & Y m. & $\mathbf{Z}$ m. & type \\
\hline 36 & 4.5950 & $87^{\circ} 39^{\prime} 10^{\prime \prime}$ & $340^{\circ} 00^{\prime} 18^{\prime \prime}$ & 502.0091 & 504.3312 & 31.7245 & control \\
\hline 37 & 4.5420 & $87^{\circ} 21^{\prime} 20^{\prime}$ & $340^{\circ} 58^{\prime} 144^{\prime}$ & 502.1085 & 504.3073 & 31.7512 & check \\
\hline 38 & 4.5953 & $87^{\circ} 26^{\prime} 04^{\prime}$ & $340^{\circ} 05^{\prime} 50^{\prime \prime}$ & 502.0132 & 504.3138 & 31.6592 & check \\
\hline 39 & 4.5407 & $87^{\circ} 25^{\prime} 25^{\prime}$ & $340^{\circ} 58^{\prime} 20^{\prime}$ & 502.0532 & 504.3044 & 31.6651 & check \\
\hline
\end{tabular}

Table 3. 3D coordinates for control and checkpoints after adjustment.

\begin{tabular}{|c|c|c|c|}
\hline Point & $\mathbf{X ~ m .}$ & $\mathbf{Y ~ m .}$ & $\mathbf{Z ~ m .}$ \\
\hline 36 & 501.9691 & 504.3012 & 31.7945 \\
\hline 37 & 501.9585 & 504.2973 & 31.7212 \\
\hline 38 & 501.9632 & 504.2938 & 31.6792 \\
\hline 39 & 501.9532 & 504.2944 & 31.6551 \\
\hline 40 & 501.9722 & 504.2908 & 31.6531 \\
\hline 41 & 501.9633 & 504.2925 & 31.6182 \\
\hline 42 & 501.9575 & 504.2886 & 31.5714 \\
\hline 43 & 501.9542 & 504.2856 & 31.5218 \\
\hline 44 & 501.968 & 504.2834 & 31.4583 \\
\hline 45 & 501.9532 & 504.277 & 31.4089 \\
\hline 46 & 501.9542 & 504.2736 & 31.3628 \\
\hline 47 & 501.9521 & 504.2712 & 31.3146 \\
\hline 48 & 501.9511 & 504.2697 & 31.2672 \\
\hline 49 & 501.9419 & 504.2691 & 31.2296 \\
\hline 50 & 501.9467 & 504.2655 & 31.1876 \\
\hline 51 & 501.9302 & 504.265 & 31.1258 \\
\hline 52 & 501.9228 & 504.2577 & 31.0864 \\
\hline 53 & 501.9452 & 504.2584 & 31.0543 \\
\hline 54 & 501.9241 & 504.2545 & 30.9897 \\
\hline 55 & 501.9402 & 504.2521 & 30.9413 \\
\hline 56 & 501.934 & 504.2464 & 30.8981 \\
\hline 57 & 501.9146 & 504.2459 & 30.8588 \\
\hline 58 & 501.9165 & 504.2467 & 30.8134 \\
\hline & & & \\
\hline
\end{tabular}

